\title{
INJERENCIA Y SOLIDARIDAD EN EL DELITO DE OMISIÓN DE AUXILIO EN CASO DE ACCIDENTE
}

\author{
THE DUTY OF RESCUE IN THE TRAFFIC OFFENCE OF FAILURE TO \\ RENDER AID
}

\author{
AleX van WeEzeL*
}

RESUMEN: La LEY Nº 20.770 de 2014 modificó la figura preexistente de omisión de auxilio en caso de accidente incrementando las penas y restringiendo la discrecionalidad en su aplicación. Con ello, el legislador desplazó uno de los posibles fundamentos de la figura, la infracción de un deber de solidaridad. El trabajo propone una interpretación de la nueva figura conforme a la cual el tipo penal protege la vigencia de la prohibición de matar o lesionar a otro, de modo que debe existir una relación de imputación objetiva entre la conducción y los resultados de muerte o lesiones que hacen surgir el deber penal de auxilio. Tal relación existe también cuando el conductor se mantiene dentro del riesgo permitido, pues la conducción de vehículos constituye un riesgo especial cuya creación determina una competencia preferente por la neutralización de las consecuencias ulteriores evitables de la conducta permitida.

Palabras clave: Omisión de auxilio, Ley de Tránsito, injerencia, solidaridad, riesgo especial.

ABSTRACT: The Law 20.770 of 2014 modified the pre-existing figure of failure to render aid in case of traffic accident increasing penalties and restricting judicial freedom in their application. The legislator displaced this way one of the possible foundations of the offence, the breach of a solidarity duty. This contribution proposes a construction according to which the criminal provision protects normatively the life and physical integrity of the participants in the road traffic, so that there must be a relation of imputation between the driving and the results of death or injuries that give rise to the criminal duty of render aid. Such a relationship also exists when the car driver respects the permitted risk, because driving constitutes a special risk whose creation determines a preferential responsibility for the neutralization of the avoidable subsequent effects of the allowed conduct.

Keywords: Failure to render aid, traffic offences, duty of rescue, solidarity.

El delito de omisión de auxilio en caso de accidente de tránsito está vigente en su configuración actual desde el 16 de septiembre de 2014, cuando la Ley Nº 20.770 introdujo modificaciones sustanciales a la figura preexistente. Esta ley tuvo su origen en una moción de la bancada de diputados del Partido Comunista, en un contexto político marcado por un fuerte rechazo ciudadano -exacerbado además por determinados acontecimientos recientes- a las consecuencias lesivas de la conducción de vehículos motorizados en estado

* Doctor en Derecho. Profesor de Derecho Penal en la Pontificia Universidad Católica de Chile. Dirección postal: Avenida Libertador Bernardo O’Higgins 340, Santiago de Chile. Dirección electrónica: avw@uc.cl Esta contribución ha sido elaborada en el marco del proyecto Fondecyt Regular $N^{\circ} 1150264$. Agradezco especialmente los comentarios y observaciones de Javier Escobar, Juan Ignacio Rosas, Rodrigo Romero, Daniela León, José Tomás Humud y Claudia Villablanca. 
de ebriedad ${ }^{1}$. Los elementos del delito se extraen del juego entre los artículos 176 y 195 de la Ley $\mathrm{N}^{\circ} 18.290$ o Ley de Tránsito², que conviene transcribir íntegramente para mayor claridad:

"Artículo 176.- En todo accidente del tránsito en que se produzcan lesiones o muerte, el conductor que participe en los hechos estará obligado a detener su marcha, prestar la ayuda que fuese posible y dar cuenta a la autoridad policial más inmediata, entendiéndose por tal cualquier funcionario de Carabineros que estuviere próximo al lugar del hecho, para los efectos de la denuncia ante el Tribunal correspondiente".

"Artículo 195.- (...)

El incumplimiento de la obligación de detener la marcha, prestar la ayuda posible y dar cuenta a la autoridad de todo accidente en que se produzcan lesiones, señalada en el artículo 176, se sancionará con la pena de presidio menor en su grado medio, inhabilidad perpetua para conducir vehículos de tracción mecánica y multa de siete a diez unidades tributarias mensuales.

Si en el caso previsto en el inciso anterior las lesiones producidas fuesen de las señaladas en el número $1^{\circ}$ del artículo 397 del Código Penal o se produjese la muerte de alguna persona, el responsable será castigado con la pena de presidio menor en su grado máximo, inhabilidad perpetua para conducir vehículos de tracción mecánica, multa de once a veinte unidades tributarias mensuales y con el comiso del vehículo con que se ha cometido el delito, sin perjuicio de los derechos del tercero propietario, que podrá hacer valer conforme a las reglas generales del Código Procesal Penal. Para los efectos de determinar la pena prevista en este inciso, será aplicable lo dispuesto en los artículos 196 bis y 196 ter de esta ley.

Las penas previstas en este artículo se impondrán al conductor conjuntamente con las que le correspondan por la responsabilidad que le pueda caber en el respectivo delito o cuasidelito, de conformidad con lo dispuesto en el artículo 74 del Código Penal”.

Las reflexiones que siguen se centran en la modalidad típica de omisión de auxilio, aunque los deberes que se infringen por omisión pueden ser también el de detener la marcha y el de dar cuenta a la autoridad policial. Cada una de estas modalidades típicas presenta sus propios problemas. Así, por ejemplo, se ha discutido si el deber de dar cuenta a la autoridad es compatible con el derecho a no autoincriminarse. El Tribunal Constitucional, en fallo dividido, rechazó recientemente la objeción de constitucionalidad realizando una interpretación restrictiva del nemo tenetur en su consagración constitucional ${ }^{3}$. También hay

\footnotetext{
$1 \quad$ Véase Historia de la Ley $\mathrm{N}^{\circ} 20.770$.

2 En lo sucesivo, también, la "Ley de Tránsito" o la "LT"; la Ley de Tránsito está contenida actualmente en el Decreto con Fuerza de Ley $N^{\circ}$ 1, promulgado el 27 de diciembre de 2007. En el texto se aludirá asimismo al Código Penal chileno mediante la abreviatura "CP".

3 REQUERIMIENTO DE INAPLICABILIDAD POR INCONSTITUCIONALIDAD RESPECTO DE LOS ARTÍCULOS 195, 196 BIS Y 196 TER DE LA LEY No 18.290, MODIFICADA POR LA LEY N 20.770 (2017). Otro aspecto resuelto en fallo dividido por el Tribunal Constitucional en esta misma sentencia -a favor de la aplicación del precepto legal- es el problema de non bis in idem que se produce cuando se condena al conductor por un cuasidelito de homicidio y, al mismo tiempo, se impone el tramo más elevado de penalidad por el delito de omisión de auxilio, atendido que se produjo el mismo resultado mortal. El rechazo del requerimiento en este punto se basó en el argumento de que este último delito es uno de omisión propia, donde el resultado no forma parte del tipo penal, de modo que
} 
problemas que derivan de la interacción entre las distintas modalidades típicas del artículo 195 en relación con el artículo 176, o entre el delito del artículo 195 y el del artículo 195 bis. Se plantea, por ejemplo, si el deber de detener la marcha forma parte del deber de prestar auxilio y, por lo tanto, no puede ser infringido en forma autónoma. Igualmente se ha advertido una eventual incompatibilidad por razones de bis in idem entre el delito de omisión de auxilio y el de negativa o retardo de los exámenes para medir el consumo de alcohol u otras sustancias 4 .

Desde luego, hay además problemas de interpretación de la misma omisión de auxilio, cuya solución depende en buena medida de la forma en que se orille el asunto que es objeto de esta contribución. Así, por ejemplo, se ha planteado en el foro si puede entenderse consumado el delito cuando el conductor se detuvo por algunos minutos y solo horas más tarde comentó a otra persona el accidente con la vaga intención de que esta solicitara ayuda y diera aviso a la autoridad. Los tribunales han resuelto que en estos casos el delito está consumado, igual que en aquellos donde se logró acreditar que el conductor detuvo la marcha, pero abandonó el lugar cuando advirtió que otro sujeto - un tercero, un transeúnte- ya se encontraba prestando ayuda a la víctima5

De cualquier modo, estas dificultades interpretativas han de llamar la atención sobre la necesidad de concretar el análisis a la luz de cada caso particular, pues las obligaciones que impone el artículo 176 LT son relativamente indeterminadas y pueden cumplirse de muchas formas distintas, especialmente desde que la LEY No 20.770 de 2014 sustituyó el concepto de ayuda "necesaria" por el de ayuda "posible". La circunstancia de que la obligación de detener la marcha puede ser, en los hechos, incompatible con la de prestar ayuda -el conductor no dispone de un teléfono, pero sabe que unos kilómetros más allá reside el médico del lugar-, es ya una señal de alerta en este sentido.

la consideración del resultado de muerte sería solo una "condición objetiva de punibilidad [más] severa de la omisión”, es decir, ella restringiría y no fundaría la punibilidad (cons. $29^{\circ}$ ). Esta argumentación no es de recibo, pues la prohibición de doble valoración no distingue entre elementos del delito y condiciones para imponer una pena más grave, como no lo hace el artículo $63 \mathrm{CP}$. Si el sustrato que se valora es el mismo, y en ambos casos para imponer una sanción penal o una sanción penal más severa, la prohibición resulta vulnerada.

4 Declarando esta incompatibilidad, CONTRA PABLO IGNACIO ARROCET SOlís (2015) considerando $5^{\circ}$.

5 Véase Contra N.A.G.O. (2016). Esta sentencia es, además, una de las que rechaza tajantemente la interpretación -ofrecida inicialmente por algunas defensas- en el sentido de que el delito del artículo 195 LT requeriría la infracción copulativa de los tres deberes que establece el artículo 176 LT; como se comprenderá, esta interpretación se deja fácilmente reducir al absurdo.

6 Esta indeterminación de la conducta mandada por el derecho podría contravenir, en la aplicación de la norma de conducta a ciertas constelaciones de casos, la garantía de tipicidad. Tratándose de esta figura, además, la (in)observancia de la garantía se deja compensar solo en menor medida con el interés en la evitación de la conducta que en el caso de la falta de omisión de socorro (artículo $494 \mathrm{~N}^{\circ} 14 \mathrm{CP}$ ), donde se establece una sanción mucho menor. 


\section{EL PROBLEMA DEL VÍNCULO ENTRE LA CONDUCCIÓN Y LOS RESULTADOS LESIVOS}

La figura del artículo 195 LT es uno de los pocos delitos de omisión propia que contempla el ordenamiento chileno. La omisión de auxilio en caso de accidente no resulta de la lectura en clave omisiva de una definición legal activa de la conducta y, sobre todo, su punibilidad no depende de los resultados que deriven de la omisión, aunque sí dependa del estado en que se encuentra la persona que debe ser auxiliada como consecuencia de la conducta anterior ${ }^{7}$.

Entre los muchos problemas teóricos y prácticos que presenta esta figura se considera aquí especialmente uno que parece ser anterior a todos los demás. Se trata de determinar qué protege el delito en su nueva configuración a partir de la Ley 20.770 de 2014 y, consecuentemente, cuál es su relación con el suceso previo, el accidente de tránsito, o, dicho con mayor precisión, cuál es la relación que debe existir entre la conducción de un vehículo que ha participado en un accidente de tránsito y los resultados cuya presencia activa el deber de auxilio penalmente garantizado.

En Chile, y en coincidencia fundamental con la discusión en el derecho comparado ${ }^{8}$, se han propuesto diferentes puntos de vista con consecuencias radicalmente diversas para la interpretación del tipo penal. En términos generales, las alternativas son dos. Un primer camino consiste en entender que la figura protege la vigencia de un deber general de solidaridad, y por lo tanto, tiene aplicación con total independencia de las características del comportamiento precedente del conductor.

Conforme a la segunda alternativa, en cambio, la figura protege la vigencia de la prohibición de matar o lesionar a otro, y por lo tanto solo tiene aplicación cuando el comportamiento precedente del conductor presenta ciertas características que permiten interpretar la omisión como una cierta infracción -eventualmente de menor entidad- al deber de no matar o no lesionar. Esta alternativa presenta a su vez diferentes modalidades. En el extremo, la figura solo habría de tener aplicación cuando el accidente -y los resultados que activan el deber de auxilio- se debe a que el conductor ha obrado de un modo que la ley considera particularmente reprochable: conducción en estado de ebriedad o bajo el efecto de sustancias prohibidas. Alternativamente, y en términos menos exigentes, puede entenderse que la figura solo tiene aplicación cuando el conductor es responsable del correspondiente cuasidelito de homicidio o lesiones.

En oposición a los planteamientos que exigen una conducta delictiva previa, cabe sostener que es suficiente con que las consecuencias del accidente sean objetivamente im-

Estas diferencias determinan la aplicabilidad de las sanciones del inciso primero (lesiones) o segundo (lesiones gravísimas o muerte) del artículo 195 LT. Pero cuando alguien ya se encuentra fallecido es imposible que se le pueda "prestar ayuda", de modo que la redacción del precepto - si no es absurda- daría a entender que la muerte ha de ser consecuencia al menos en parte de la omisión de auxilio. Como se verá, sin embargo, la ley equipara por otro lado la producción de la muerte con la de lesiones gravísimas, de modo que el texto legal adquiere sentido también sin esta relación de imputación: quien omite prestar auxilio al gravemente lesionado responde en idénticos términos tanto si luego se produce la muerte como si esta no se produce.

8 Sobre ella véase Escobar (2017) pp. 20 y ss., con particular referencia a los ordenamientos italiano y español. 
putables al conductor, lo que exige constatar una posición de garante que se encuentre activa conforme a las instituciones dogmáticas de imputación objetiva de conductas y de resultados. Esta última modalidad de la segunda alternativa admite un refinamiento ulterior, consistente en considerar que las consecuencias del accidente también son objetivamente imputables al conductor cuando este solo ha creado un riesgo permitido, pues la conducción de un vehículo motorizado constituye lo que se denomina un "riesgo especial".

Parece desde ya evidente que la viabilidad de la alternativa que exige responsabilidad del conductor por el cuasidelito depende de la correcta interpretación del inciso final del artículo 195 LT, mientras que la viabilidad de la última modalidad -basta la creación de un riesgo especial- pasa por armonizar el delito previsto en el artículo 195 LT con la figura meramente contravencional del artículo $201 \mathrm{~N}^{\circ} 15$ LT. La claridad de la exposición exige, sin embargo, avanzar paso a paso.

\section{LA LESIÓN DE UN DEBER DE SOLIDARIDAD QUE SE ACTIVA CAUSALMENTE}

De acuerdo a una primera perspectiva, la realización del delito previsto en el artículo 195 LT no dependería en absoluto del comportamiento previo del conductor, de modo que bastaría con su involucramiento causal en el accidente y en la producción de las lesiones o la muerte. Esta "participación” causal, desde luego, no sería suficiente para atribuir responsabilidad por el correspondiente delito de resultado, pero sí para activar un deber general de solidaridad cuya infracción está tipificada como delito en el precepto citado.

Con independencia de la discusión sobre la solidaridad como fuente de una posición de garante en derecho penal ${ }^{9}$, todo indica, sin embargo, que la configuración legal del ilícito de omisión de auxilio resulta incompatible con un fundamento de esta especie:

a) Si el fundamento del tipo penal fuera la solidaridad entre los miembros de la comunidad, no tendría sentido imponer las obligaciones de auxilio únicamente al conductor involucrado en el accidente de tránsito. Pues no es infrecuente que en los vehículos viajen personas distintas del conductor y, sin embargo, los deberes del artículo 176 no les alcan$\mathrm{zan}^{10}$. Al establecer el deber de auxilio exclusivamente respecto del conductor - ni siquiera queda comprendido el dueño del vehículo, aunque viaje en ese momento como pasajero-, la definición del comportamiento típico permanece necesaria e indisolublemente vinculada a la conducta previa: conducir el vehículo.

b) En directa relación con lo anterior, si el delito de omisión de auxilio tuviera el mismo fundamento que la falta de omisión de socorro, resultaría imposible explicar la enorme diferencia de tratamiento punitivo para unos y otros. La falta de omisión de socorro contempla una sanción de multa de una a cuatro UTM, mientras la omisión de auxilio

\footnotetext{
$9 \quad$ Al respecto, Coca Vila (2016) pp. 258 y ss.; Wilenmann (2017) pp. 76 y ss.; van Weezel (2014) pp. 194 y ss., todos con abundantes referencias ulteriores. Desde una perspectiva histórica, RENZIKOWSKI (2013) pp. 13 y ss.

10 Véase Escobar (2017) p. 16.
} 
contempla penas privativas de libertad que incluso, según una interpretación posible de la ley, deberían quedar sujetas a cumplimiento efectivo durante un año ${ }^{11}$.

c) La graduación de las sanciones en el artículo 195 LT también es inconsistente con la infracción de un deber de solidaridad. Por una parte, se establece que su magnitud depende de la entidad de los resultados que terminen produciéndose como consecuencia del accidente. Si el fundamento de la figura fuera la infracción de un deber de solidaridad, esta configuración de las sanciones carecería de fundamento, pues el deber de solidaridad se infringe con independencia de las características del accidente previo. Por otro lado, y confirmando lo anterior, al establecer la cuantía de las penas la ley equipara los resultados de lesiones gravísimas con el resultado de muerte y, por lo tanto, hace caso omiso de que la infracción del deber de solidaridad respecto de un lesionado grave -la omisión de auxilio- haya podido tener precisamente como consecuencia su muerte ${ }^{12}$. Lo único que parece importar a este respecto es la actuación precedente y sus consecuencias directas.

La situación era muy diferente bajo la vigencia del antiguo artículo 196 D 1, anterior a la Ley $N^{\circ} 20.770$ de 2014, cuya redacción permitía interpretar que el tribunal, según su estimación, podía sancionar la omisión de auxilio con una pena de suspensión de la licencia de conducir o con una pena de tres años de reclusión. Las penas privativas de libertad de cierta consideración, en cambio, quedaban reservadas para los casos en que al conductor sancionado le cabía alguna responsabilidad en el accidente mismo, en la situación de necesidad: hipótesis de conducción temeraria o antirreglamentaria con resultados no imputables, o que no excedían las lesiones simplemente graves. Por el contrario, allí donde solo se podía constatar el quebrantamiento de un deber de solidaridad, la sanción debería mantenerse por debajo de la privación de libertad o, en casos excepcionales, en el mínimo de esta.

Con el cambio legislativo -especialmente en cuanto a la magnitud de las penas, superiores a las de los respectivos delitos imprudentes, y la eliminación de la imposición facultativa de la pena privativa de libertad-, esa propuesta interpretativa ha dejado de ser viable.

En síntesis, entonces, la nueva configuración de las normas de conducta y de la norma de sanción parece incompatible con la posibilidad de considerar que el fundamento de la sanción es la infracción de un deber de solidaridad activado causalmente. La figura tiene

\footnotetext{
11 Se trata de un asunto particularmente delicado. El artículo 195, inciso tercero, relativo a los casos en que el accidente ha provocado lesiones gravísimas o muerte, dispone que "para los efectos de determinar la pena prevista en este inciso, será aplicable lo dispuesto en los artículos 196 bis y 196 ter de esta ley”. Este último precepto establece a su vez que "la ejecución de la respectiva pena sustitutiva quedará en suspenso por un año, tiempo durante el cual el condenado deberá cumplir en forma efectiva la pena privativa de libertad a la que fuere condenado". En la práctica, sin embargo, los tribunales hacen caso omiso de estas remisiones y sustituyen la pena, salvo cuando junto al delito de omisión de auxilio concurre un manejo en estado de ebriedad. A la luz de la jurisprudencia constitucional reciente, esta opción parece una forma de interpretar la ley de un modo conforme con la Constitución.

12 Véase Contra Pablo IGNACio Arrocet Solís (2015), que razona acertadamente en el sentido de que el delito entra igualmente en consideración en su forma agravada con total independencia de que el accidente haya provocado lesiones necesariamente mortales, es decir, que no se hubiera evitado la muerte "aun con socorros oportunos y eficaces" (considerando $5^{\circ}$ ).
} 
que encontrar su explicación y fundamento en alguna característica de la conducta precedente, del "accidente" 13 .

\section{LA MUERTE O LAS LESIONES SE DEBEN A LA CONDUCCIÓN EN ESTADO DE EBRIEDAD O BAJO EL EFECTO DE SUSTANCIAS PROHIBIDAS}

La Ley No 20.770 de 2014 habría tenido como objetivo desterrar la sensación de impunidad ante el delito de manejo en estado de ebriedad con resultado de muerte. En palabras del Mensaje, "la sociedad no comprende cómo una persona que voluntariamente bebió hasta embriagarse, que voluntariamente condujo un vehículo y lesionó o incluso mató a una persona, no sea considerado autor de un delito grave que le impida obtener su libertad"14. El establecimiento del nuevo delito de omisión de auxilio se produce en este preciso contexto y, por lo tanto, se dice, el tipo penal debe interpretarse practicando una reducción teleológica consistente con él: solo comete el delito de omisión de auxilio el conductor que previamente se ha hecho responsable del delito de conducción en estado de ebriedad o bajo los efectos de sustancias estupefacientes o psicotrópicas.

Esta propuesta interpretativa parece, sin embargo, poco plausible por cuatro razones complementarias:

a) El sentido literal posible del precepto no la sustenta.

b) El delito de omisión de auxilio es muy anterior a la Ley $\mathrm{N}^{\circ} 20.770$ de 2014, pues fue introducido en el año 2005 mediante la Ley $N^{\circ} 20.068$. Es cierto que tanto la definición de la nueva figura como las nuevas penas excluyen una interpretación del delito como infracción de un deber de solidaridad mínima; pero no hay antecedentes para asumir una traslación tan radical del fundamento de la figura hacia la exigencia de un desvalor de acción particularmente cualificado.

c) La historia de la Ley $N^{\circ} 20.770$ de 2014 da cuenta de que el proyecto de ley original no sustituía ni derogaba la regla equivalente al artículo 195 LT, sino que proponía incorporar además la fuga y omisión de auxilio como agravante aplicable al delito de manejo en estado de ebriedad causando lesiones gravísimas o muerte, alternativa que se desechó durante la tramitación del proyecto. Bajo esta sistemática, la fuga y omisión de auxilio podía configurar una agravante, o bien, el delito autónomo del artículo 195 LT. Por lo tanto, la omisión de auxilio no fue concebida como un tipo penal subordinado al manejo en estado de ebriedad causando lesiones gravísimas o muerte.

Por otra parte, la sustitución del artículo 195 LT fue la manera de conservar la sistemática de la ley ante una indicación del Ejecutivo que pretendía incorporar las nuevas sanciones en el mismo artículo 176 LT.

13 Estas consideraciones permiten desechar también el argumento de la tesis "solidarista" causal en el sentido de que el artículo 195 LT se refiere a un "accidente del tránsito", voz que aludiría a un suceso inocente. Aparte de que en tal caso habría que entender que si el conductor es culpable del accidente quedaría exento del deber de auxilio -lo cual sería un manifiesto despropósito-, la ley penal utiliza la expresión "accidente" para referirse a un suceso que ha sido provocado imprudentemente, con infracción de los deberes de diligencia jurídico-penalmente relevantes, como ocurre en los artículos 325 y 329 CP.

14 Historia de la Ley $N^{\circ} 20.770$, p. 4; sobre ello véase MATus (2014) pp. 101 y ss. 
d) Si el argumento de contexto e historia legislativa fuera correcto, entonces la reducción teleológica debería aplicarse con mayor razón a las figuras que fueron recién creadas por la Ley $\mathrm{N}^{\circ} 20.770$ de 2014 , cuyo surgimiento se explica precisa y directamente por este contexto e historia ${ }^{15}$. Tal es el caso del delito de negativa injustificada del conductor a someterse a pruebas y exámenes para comprobar la presencia de alcohol u otras sustancias, de realizar maniobras tendientes a alterar los resultados de las pruebas, y de dilatar su práctica, previsto en el artículo 195 bis LT.

Si este delito solo pudiera ser cometido por quien conducía en estado de ebriedad o bajo el efecto de sustancias prohibidas, se estaría ante un caso legalmente consagrado de "prueba diabólica" -se exige acreditar el presupuesto de un delito (que se ha conducido en estado de ebriedad) consistente precisamente en hacer imposible la acreditación de ese presupuesto (sustraerse a los procedimientos que podrían acreditar que se ha conducido en estado de ebriedad) - y el delito carecería, por lo mismo, de toda relevancia práctica.

\section{RESPONSABILIDAD DEL CONDUCTOR POR UN CUASIDELITO DE HOMICIDIO O LESIONES}

Conforme a una alternativa menos exigente que la anterior, solo si se verifican los presupuestos típicos del artículo 490 o del artículo 492 del Código Penal respecto de la muerte o las lesiones, vendría a cuento una posible responsabilidad por omisión de auxilio conforme al artículo 195 LT.

Los delitos respectivos se encontrarán usualmente en una relación de concurso real, ya que la consumación del segundo tendrá lugar en un contexto espacio-temporal suficientemente diferenciado en relación con la consumación del primero ${ }^{16}$. Así lo establece por lo demás la regla del artículo 195 inciso final LT, conforme a la cual las penas del delito de omisión de auxilio "se impondrán al conductor conjuntamente con las que le correspondan por la responsabilidad que le pueda caber en el respectivo delito o cuasidelito, de conformidad con lo dispuesto en el artículo 74 del Código Penal"17.

La solución concursal presenta indudables ventajas, entre las que destaca su claridad y certeza. Ella conduce -dentro de lo que cabe- a una especie de "formalización" de la posición de garante del conductor, lo que contribuye a una aplicación previsible de la figura, con la consiguiente ganancia en orientación para el ciudadano. Al menos quien sea consciente de haber provocado culpablemente el accidente, por ejemplo, por haber infringido

\footnotetext{
15 Véase Escobar (2017) p. 13.

16 Criterio reafirmado recientemente en forma explícita por la Corte Suprema (CONTRA MAURICIO ORLANDO ORTEGA RUIZ [2017]).

17 Parece que el legislador pretende forzar de este modo un régimen de concurso real a todo evento. Sin embargo, es evidente que la solución en cada caso dependerá de la forma en que ocurrieron los hechos. Por ejemplo, si el impacto del vehículo conducido imprudentemente produce en la víctima una lesión leve, que solo se agrava por la falta de ayuda oportuna, se imputará la consecuencia más grave al conductor negligente, pero esta misma imputación impedirá valorar nuevamente la omisión de prestar auxilio para imputar el delito del artículo 195 LT y habrá que apreciar un concurso de leyes.
} 
lo establecido en una señal de tránsito, tendrá perfectamente claro que debe auxiliar a los lesionados y que, si ni lo hace, cometerá un nuevo ilícito.

Sin embargo, esta solución tampoco está exenta de inconvenientes:

a) En primer lugar, surge una sospecha de vulneración del principio de non bis in idem en su dimensión de prohibición de doble valoración: el conductor es responsable de la omisión de auxilio por la misma causa que lo hace responsable de un delito diferente, el homicidio y las lesiones imprudentes.

Tal sospecha podría aplacarse aduciendo que la observación del derecho vigente muestra cómo en realidad se tolera un cierto nivel de valoraciones redundantes en perjuicio del justiciable, tal como ocurre en la regla del artículo 75 del Código Penal y en el delito de lavado de dinero, para mencionar dos ejemplos connotados. Aquí podría tratarse, entonces, de una hipótesis adicional. Mientras la doble valoración no supere un cierto umbral de tolerancia -que habría que definir-, no existirían problemas de culpabilidad o proporcionalidad, según el fundamento que se atribuya al principio non bis in idem. Sin embargo, esta ponderación deberá realizarse caso a caso, lo que socava una de las principales ventajas de esta opción interpretativa.

b) Pero también la socava una particular indeterminación de los presupuestos de tipicidad del delito imprudente, con independencia de cuáles sean sus causas. En nuestro ordenamiento es enigmático el requisito de "temeridad" de la imprudencia, contenido en el artículo 490 CP; pero también la definición de la "mera imprudencia o negligencia" remite -al menos según la doctrina predominante- a un cúmulo de criterios de contenido incierto ${ }^{18}$. En el concreto ámbito del tráfico motorizado, además, el artículo 492 exige distinguir entre los elementos constituyentes de la mera imprudencia o negligencia y el contenido de los reglamentos -las leyes del tránsito-, de manera que no es asunto de integrar simplemente el deber de cuidado cuya infracción determina el actuar imprudente con una o más normas de conducta puntuales de la LT.

c) Aun más problemática puede ser la consideración de que esta alternativa vendría a establecer una exigencia desproporcionadamente elevada para la activación de un deber de prestar auxilio que parece imponerse de modo natural a cualquier ciudadano que se ha visto involucrado en un accidente de tránsito. Salvo en los casos en que el conductor deba atender un deber preferente o esté impedido por otra causa, parece razonable exigirle -incluso bajo amenaza de pena- prestar ayuda a quien ha sacado la peor parte en un accidente de tránsito en el cual ha tenido participación como conductor, con independencia de que pueda imputársele un cuasidelito.

Esta reflexión adquiere más fuerza si se considera que la evitabilidad individual propia de la imprudencia debe enjuiciarse conforme a parámetros individualizadores ${ }^{19}$. Así, para una persona que no pudo evitar el accidente atendidas sus circunstancias de conocimiento y habilidad -de modo que no podrá imputársele cuasidelito alguno- podría ser

\footnotetext{
18 Véase por ejemplo, Stratenwerth y Kuhlen (2011) p. 311: "Todo lo anterior significa, en conjunto, que la medida del cuidado debido en último término se determina a través de las circunstancias del caso singular". 19 Véase VAN WeEzel (2008) p. 72; también en tal sentido Mañalich (2015) p. 22; y ReYes (2015) p. 63, quien destaca la importancia de evitar la confusión entre un criterio individualizador y uno psicológico.
} 
perfectamente evitable la omisión de prestar la ayuda posible a los lesionados en ese mismo accidente. La inevitabilidad individual de los resultados producidos por el accidente no puede tener, por sí sola, el efecto de eximir al conductor de toda responsabilidad por la evitación o neutralización de los efectos asociados a la conducción del vehículo. Por cierto que la afirmación de una eventual responsabilidad por tales efectos requiere un fundamento suficiente; pero si fuera posible proveer tal fundamento -y aquí se entiende que es posible, según se verá-, este podría dar lugar a un deber distinto del que consiste en conducir dentro de los límites del riesgo permitido: un deber de neutralizar ciertos riesgos que puede adoptar, precisamente, la forma de un deber de prestar auxilio.

Algo similar puede predicarse de otros requisitos típicos del delito imprudente. Pues el conductor tampoco será responsable de un cuasidelito de homicidio o lesiones cuando no incurra en una infracción formal a la regulación del tránsito, si es que no ha actuado de un modo temerariamente imprudente. La imprudencia simple no es punible por regla general en Chile, y tampoco lo es en el ámbito del tránsito.

d) El tenor literal del inciso final del artículo 195 LT parece también cerrar el camino a la tesis concursal. Conforme a esta regla, las penas del delito de omisión de auxilio "se impondrán al conductor conjuntamente con las que le correspondan por la responsabilidad que le pueda caber en el respectivo delito o cuasidelito, de conformidad con lo dispuesto en el artículo 74 del Código Penal”.

La expresión "la responsabilidad que le pueda caber [al conductor] en el respectivo delito o cuasidelito" es inequívoca en cuanto a que se trata de una posibilidad. Tal responsabilidad por el respectivo delito o cuasidelito es eventual, podría estar ausente y, no obstante ello, ser el conductor responsable por el delito de omisión de auxilio. Si el concurso -real o de cualquier otra especie- entre la responsabilidad cuasidelictual y el delito doloso de omisión de auxilio es meramente contingente, entonces resulta evidente que la primera no es un presupuesto del segundo.

Estas consideraciones de texto, sumadas a los demás argumentos sistemáticos y valorativos, permiten descartar esta forma de articular la responsabilidad por el accidente con el delito de omisión de auxilio.

Por las mismas razones se ha de descartar la posibilidad de extraer de la expresión "conductor que participe en los hechos" alguna conclusión en cuanto a que debe tratarse de una participación punible ${ }^{20}$. Es cierto que el Código Penal utiliza con frecuencia esta expresión atribuyéndole este último sentido ${ }^{21}$. Pero el uso de la palabra "participar" es ya mucho menos unívoco en el Código Procesal Penal ${ }^{22}$, mientras que en la LT claramente alude a una intervención en términos amplios, no necesariamente punible: artículos 174 y 180 LT $^{23}$.

\footnotetext{
20 Con matices Escobar (2017) pp. 27 y ss., quien en todo caso rechaza una interpretación del término "participar" en clave exclusivamente causal.

${ }_{21}$ En el Código Penal, por ejemplo, los artículos $10 \mathrm{~N}^{\circ}$ 5, $12 \mathrm{~N}^{\circ} 21,17,150$ inciso segundo, 168, 176, 183 inciso primero, 269 ter, 366 quinquies y 489 inciso segundo.

22 En el Código Procesal Penal, por ejemplo, los artículos 179 inciso primero, 180 inciso segundo, 198 inciso primero y 259 letra d).

23 Este último precepto dispone que "los conductores y peatones que hayan tenido intervención en un accidente del tránsito, deberán facilitar las investigaciones, inspecciones y estudios que estime necesario realizar en
} 


\section{LA MUERTE O LAS LESIONES HAN DE SER OBJETIVAMENTE IMPUTABLES AL CONDUCTOR}

Ante el panorama descrito se ofrece la posibilidad de vincular el delito de omisión de auxilio ya no a la responsabilidad penal por un delito o cuasidelito "base", sino a la competencia del sujeto por el suceso desde el estricto punto de vista de la imputación objetiva. Con otras palabras, el conductor debe estar en alguna posición de garante respecto de la concreción de ciertos riesgos inherentes a la conducción y esa posición de garante debe encontrarse activa conforme a los criterios que emanan de las instituciones dogmáticas de la imputación objetiva de conductas y de resultados.

\section{a) EL CRITERIO DE BASE}

Por cierto que existe discusión sobre diversos aspectos de la imputación objetiva: si puede hablarse de una imputación objetiva de conductas o, por el contrario, todos los criterios relevantes corresponden a la imputación de resultados; si determinadas instituciones no se agotan simplemente en criterios generales de interpretación de los tipos penales; si la imputación a la víctima o el principio de confianza solo pueden tener aplicación en el ámbito de la imprudencia, etc.

Sin embargo, parece haber amplio acuerdo en que la sola contribución causal a una lesión es insuficiente para fundar responsabilidad penal ${ }^{24}$, y en que un hecho puede incluso no ser imputable a un garante ya en el plano objetivo si es que no ha transgredido con su conducta el riesgo permitido, estaba autorizado para confiar en el comportamiento correcto de otros garantes o se limitó a respetar la autonomía de la potencial "víctima". Otro tanto vale para los resultados, cuando se encuentra establecido que el riesgo realizado no es aquel que el sujeto creó con su conducta, sino uno distinto. Aunque pueda ser complejo establecer si en el caso concreto se verifica alguna de estas situaciones, existe amplio acuerdo en cómo han de ser tratadas jurídico-penalmente una vez que han sido establecidas.

Esta alternativa de interpretación presenta la indudable ventaja de mantener una vinculación entre la actividad previa de conducir y el delito de omisión de auxilio -la cual, según se vio, viene exigida por la configuración legal de este último delito-, pero al mismo tiempo evita establecer presupuestos que podrían resultar excesivos o desproporcionados, especialmente en cuanto a las exigencias de imputación subjetiva. No es necesario haber incurrido en un cuasidelito de homicidio o de lesiones para estar obligado a auxiliar bajo amenaza de pena; pero la ley tampoco impone un deber de solidaridad con graves consecuencias penales en caso de incumplimiento.

los vehículos y las personas, la Unidad Técnica de Investigaciones de Accidentes de Tránsito de Carabineros”.

24 Incluso para quienes, como entre nosotros Hernández (2006) pp. 9 y ss., reivindican la relevancia del dato causal ante los planteamientos de corte normativista; en Alemania véase, por ejemplo, Wessels, BeULKE y SATZGER (2015) pp. 72 y ss. Sobre la estructura de la imputación de conductas que subyace a los planteamientos del texto, y que resulta aplicable tanto a las conductas activas como omisivas, véanse más en detalle: JAKOBS (2013) p. 82; JAKOBS (2012) pp. 26 y ss., 83 y ss.; con un desarrollo propio a partir de estos planteamientos PAWLIK (2012) pp. 159 y ss.; Wilenmann (2014) pp. 33 y ss.; Kubiciel (2013) pp. 173 y ss.; sobre el origen y la historia de la teoría de los deberes penales SÁnCheZ-Vera (1999) pp. 67 y ss.; VAN WeEZel (2013) pp. 283 y ss. 
No son pocos, sin embargo, los desafíos teóricos y prácticos que debe enfrentar una concepción como esta, comenzando por la definición de si la imputación objetiva de las consecuencias -y la responsabilidad por la omisión de auxilio consiguiente- exige que el conductor haya creado un riesgo prohibido o si, por el contrario, dicha imputación puede afirmarse también cuando el riesgo de la conducción se mantuvo dentro de los límites permitidos por el ordenamiento.

\section{b) Creación de un Riesgo especial, Pero permitido}

Ya se ha visto cómo una lesión de la solidaridad mínima no puede sustentar penas de la magnitud de las previstas en el artículo 195, ni explica la diferencia entre el régimen del conductor no responsable del accidente y el régimen extraordinariamente benigno del "mal samaritano" en la falta de omisión de socorro.

Igualmente infundado parece, incluso más allá de la tesis de la solidaridad, que la ley imponga el deber de auxilio solo al conductor y no a cualquier persona a la que sean objetivamente imputables las lesiones graves. Pues podría perfectamente ocurrir que el conductor -por ejemplo, un taxista- haya excedido mínimamente la velocidad permitida, pero que el accidente tenga su explicación en el asalto que estaba sufriendo a manos de su pasajero; o que el conductor haya atropellado a la víctima como consecuencia de una maniobra instintiva destinada a esquivar a otro peatón que cruzaba por una zona prohibida. Ni este último peatón ni el asaltante del ejemplo tendrán el deber de auxilio, a pesar de que el respectivo accidente es objetivamente imputable a cada uno de ellos. La posición de garante exigida por el tipo penal considera, pues, algo más.

Una posible explicación de todos estos aspectos, centrales en la configuración legal de la figura, es la subsistencia de la posición de garante por injerencia, a pesar de que el sujeto actúa dentro del riesgo permitido, en los casos en que se crea un "riesgo especial"25. Los riesgos especiales son los que exceden del mínimo de riesgos que cada uno impone a los demás de un modo inherente al contacto social y se reconocen, por ejemplo -aunque no siempre-, en que el derecho establece la obligación de contratar seguros para cubrirlos, o en que la regulación del límite hasta el cual el riesgo está permitido es particularmente densa o meticulosa.

A esta clase de riesgos pertenecen el test de ciertos medicamentos en seres humanos y la manipulación de material radiactivo, pero también la actividad de lanzar productos al mercado que, a pesar de haberse observado todos los resguardos y medidas de cuidado exigibles, resultan ser dañinos para los usuarios o consumidores ${ }^{26}$. Determinar si una actividad consti-

25 Véase Jakobs (2012) p. 37; similar Freund (2009) pp. 227, 234 y ss., quien lo aplica especialmente a la responsabilidad penal por la puesta en circulación de un producto defectuoso; también KöHLER (1997) pp. 219 y ss.: Los deberes de aseguramiento en el tráfico pueden convertirse en deberes de garante si es que la situación avanza hacia una ulterior concreción del riesgo, "pues con el riesgo permitido no se conecta ninguna autorización de intervención en la esfera ajena, por lo que cualquier puesta en peligro concreta que vaya más allá se encuentra prohibida". Crítico ante la categoría del riesgo especial Contreras (2017) pp. 23 y s., en especial debido a lo que considera como falta de concreción; su propia solución (pp. 43 y ss.), sin embargo, da cuenta de un esfuerzo -bien logrado- por dotar de concreción a la misma idea de "especial responsabilidad" que subyace a la categoría del "riesgo especial".

26 Véase específicamente sobre la posición de garante de quien lanza un producto al mercado, VAN WEEZEL (2007) pp. 65 y s.; Contreras (2017) pp. 1 ss. 
tuye un riesgo especial puede ser, en algunos casos, complejo. Sin embargo, no hay duda de que la conducción de vehículos motorizados pertenece a esta categoría ${ }^{27}$. Al autorizar la conducción de vehículos motorizados, el derecho autoriza la creación de riesgos muy por encima de lo que resulta controlable para la persona que conduce y compensa esta autorización con la imposición de una competencia preferente por las consecuencias típicas de ese riesgo.

En realidad, los casos de creación de un riesgo especial son casos de especial responsabilidad de una persona por un cierto riesgo o conjunto de riesgos ${ }^{28}$. Por eso -pues lo decisivo es la competencia por el riesgo-, la contrapartida de la injerencia por creación de un riesgo especial es el estado de necesidad defensivo ${ }^{29}$. Cuando una conducta que se mantiene dentro del riesgo permitido se torna altamente peligrosa para los bienes o intereses de un tercero, quien sufre la amenaza no está obligado a tolerar la pérdida de sus bienes y puede legítimamente conjurar el peligro apelando a la autorización que le proporcionan las reglas sobre estado de necesidad defensivo, precisamente, a costa de quien actúa amparado por el riesgo permitido. La clase de responsabilidad o competencia del afectado por la acción de salvaguarda es, sin embargo, objeto de viva discusión ${ }^{30}$.

Pero más allá de las diferencias terminológicas y sistemáticas, en la medida en que en las hipótesis comprendidas bajo el rótulo del riesgo especial no es posible organizar la propia esfera de un modo tal que se excluya razonablemente todo riesgo para los demás, al permitir la creación de esta clase de riesgos el derecho compensa este diferencial dejando subsistente la posición de garante respecto de las consecuencias ulteriores y evitables que sean imputables a ellos ${ }^{31}$. Quien eleva un dron cumpliendo con todas las regulaciones debe auxiliar a las víctimas si el aparato imprevisiblemente falla y cae, lesionando a unos transeúntes. Algo análogo ocurre con las consecuencias que se derivan de conductas justificadas cuando la salvaguarda del bien ya se encuentra asegurada. Quien ya ha conjurado el mal amenazante debe impedir, en la medida en que le resulte posible, que la acción de salvaguarda siga produciendo efectos de un modo inútil -y, por tanto, desproporcionado- hasta llegar, por ejemplo, al aniquilamiento de la fuente de peligro $^{32}$.

27 Similar Dopico (2002) pp. 265 y ss., aunque este autor se refiere a una verdadera responsabilidad objetiva o responsabilidad por el riesgo (p. 271).

28 En tal sentido entiendo los planteamientos de CONTRERAs (2017) pp. 43 y ss.; en el mismo sentido VAN WeEZEL (2006) p. 214, nota 124.

29 En tal sentido JаковS (2012) p. 37. El paralelismo entre el problema aquí tratado y la discusión sobre la competencia por la situación de peligro en el estado de necesidad defensivo se aprecia claramente en la estructura del tratamiento de este último en WiLENMANn (2017) pp. 488 y ss.

30 La cuestión se encuentra ya planteada y desarrollada en la obra de BALDó (1994) pp. 73 y ss., pp. 121 y ss., pp. 168 y ss.; de Dopico (2002) pp. 235 y ss., y también en trabajos de Robles Planas (2010) pp. 445 y ss., y de Wilenmann (2014) pp.105 y ss.; Él mismo (2017) pp. 67 y ss.

31 La competencia preferente derivada de la creación de un riesgo especial concurre además a dar relevancia a ciertos elementos que, de otro modo, serían completamente irrelevantes para la imputación. Por ejemplo, obliga a activar y utilizar conocimientos especiales en orden a evitar la realización del riesgo especial, ampliando el segmento de la realidad por el cual responde el autor (Véase por ejemplo JAKOBs [2017a] pp. 163 y ss).

32 El asunto puede ser más discutible cuando se trata de la legítima defensa, pues en tal caso la competencia por el riesgo corresponde por completo al mismo agresor. Pero si se extendiera también a ella este criterio, el conocido caso Chépica (CONTRA CARLos Humberto CASTRo MuÑoz [1998], con comentario de Vargas [2015] pp. 183 y ss.) debería resolverse del mismo modo tanto si se afirma como si se descarta la legítima defensa previa. 
Cabría objetar, sin embargo, que este planteamiento termina por volver irrelevante la infracción del riesgo permitido: la transgresión o su ausencia no solo da lo mismo a los efectos de desencadenar el deber de auxilio, sino también para afirmar o negar la responsabilidad por el delito o cuasidelito. Se trata de la antigua cuestión acerca de los requisitos de la injerencia y, concretamente, si ella exige un comportamiento previo contrario a derecho. Desde el punto de vista de la teoría de la imputación objetiva, la pregunta es si la actuación dentro del riesgo permitido produce el efecto de desactivar, en todo caso, la correspondiente posición de garante.

La discusión al respecto puede seguirse en su versión más moderna hasta comienzos de los años 70 del siglo pasado ${ }^{33}$; en sus rasgos fundamentales -concretamente, sobre la existencia de un deber de neutralizar los efectos derivados de la creación un riesgo permitido-, se remonta cuando menos a los trabajos de Merkel a fines del siglo XIX ${ }^{34}$. En cualquier caso, y a pesar de algunas declaraciones generales en sentido contrario ${ }^{35}$, existe amplio acuerdo en cuanto a que al menos algunos comportamientos lícitos o permitidos dan lugar al deber jurídico-penalmente relevante de remover o evitar consecuencias lesivas. Esto ocurre visiblemente, según se anticipó, cuando la afectación de un tercero está amparada por una causa de justificación distinta de la legítima defensa que, sin embargo, se encuentra agotada por la desaparición de sus presupuestos.

La propuesta que aquí se realiza asume este mismo punto de vista y lo hace extensivo, también, a los casos en que quien actúa dentro del riesgo permitido ha creado, no obstante, un riesgo especial. Esto se debe a que el riesgo especial se encuentra permitido a pesar de que a todas luces quien lo crea no está en condiciones de controlarlo por completo. El ordenamiento compensa este déficit con la obligación penalmente garantizada de neutralizar en lo posible las concreciones ulteriores de ese riesgo. El riesgo especial se comporta así del mismo modo, en relación con los deberes de aseguramiento y neutralización, que la conducta amparada por una causa de justificación ${ }^{36}$. La realización de la conducta riesgosa

Sobre el problema en general, van WeEZEL (2006) p. 215; con respecto al caso citado y también en la línea de la doctrina mayoritaria -es decir, descartando una posición de garante de quien ha hecho uso de la legítima defensa- Wilenmann (2017) pp. 360 y s., con ulteriores referencias. Distinguiendo explícitamente entre los casos de legítima defensa (no hay posición de garante) y los casos de actuación dentro del riesgo permitido (la posición de garante por injerencia respecto de las concreciones ulteriores del riesgo subsiste en ciertos casos, que coinciden con lo que aquí se considera creación de un riesgo especial), Kudlich (2012) \$13, n. 23.

33 Véase al respecto PAWLIK (2012) pp. 181 y ss., con ulteriores referencias; particularmente relevantes son las contribuciones de Welp (por ejemplo Welp [1971] pp. 432 y ss). y Herzberg (por ejemplo Herzberg [1986] pp. 986 y ss.). Entre nosotros, IzQuierdo (2006) p. 333, y Hernández (2011) p. 30, ambos con ulteriores referencias de la doctrina chilena.

34 Merkel (1899) pp. 81 y ss.

35 Véase Stree y Bosch (2014) p. 219; en Chile especialmente Cury (2005) p. 683.

36 Con ambos grupos de casos -creación de un riesgo especial y conductas justificadas (con la posible excepción de la legítima defensa) - se agota el espectro de las conductas permitidas que dejan subsistente una posición de garante en orden a la neutralización del riesgo para evitar consecuencias lesivas ulteriores. En el primer grupo, el carácter especial del riesgo restringe el alcance de su permisión; en el segundo, la permisión condicionada, propia de la justificación, limita el efecto liberador de responsabilidad a lo estrictamente necesario. De otra opinión Herzberg (1986) pp. 988 y s., para quien la injerencia siempre va acompañada de responsabilidad por las consecuencias ulteriores de la conducta; similar WeLP (1971) p. 433, quien dispensa análogo tratamiento a todos los casos en que la conducta permitida da lugar a "consecuencias típicamente relevantes que, ex post, son 
está permitida y las consecuencias lesivas imputables a ella no dan lugar a responsabilidad por el delito de resultado, pero sí imponen un deber de neutralización jurídico-penalmente relevante de los efectos ulteriores que sean evitables.

Cuando un conductor golpea con su vehículo a un ciclista -por ejemplo, porque las condiciones de visibilidad eran extraordinariamente deficientes- a pesar de que en principio ambos han observado las reglas del tránsito, el conductor debe asegurarse de que el ciclista salga de la vía de circulación para impedir que sea atropellado por un tercero; si no lo hace, responderá por las lesiones que el ciclista sufra como consecuencia del segundo atropello, aunque no le quepa responsabilidad alguna en las lesiones que su propio vehículo le provocó. A la misma constelación pertenecen los casos de puesta en circulación masiva de un producto con observancia de todos los resguardos técnicos exigidos, pero cuya insuficiencia -comprobada con posterioridad a un evento lesivo- lo hace peligroso para los consumidores. El fabricante, igual que el conductor apegado a las normas, no responderá por el evento lesivo, pero debe neutralizar ulteriores y evitables concreciones del riesgo retirando el producto de circulación.

Esto lleva a la necesidad de precisar el objeto de la competencia del conductor que se ha mantenido en los límites del riesgo permitido. Cuando se afirma que el conductor debe estar en alguna posición de garante respecto de la concreción de ciertos riesgos inherentes a la conducción y que esa posición de garante debe encontrarse activa conforme a los criterios de imputación objetiva, esta afirmación se refiere a aquellas concreciones cuya producción requiere del transcurso de un cierto lapso de tiempo durante el cual es posible intervenir en orden a su evitación. Quien ha creado un riesgo especial no queda exento del deber de neutralizar estas concreciones de los riesgos que ha creado -como el desangramiento, o cualquier otra forma de agravamiento de una lesión por falta de intervención oportuna-, aunque el riesgo permitido desactive su posición de garante en relación con los efectos inmediatos de la conducción, como las lesiones producidas directamente por el impacto.

Así, también el conductor que ajusta su comportamiento a las reglas del tráfico motorizado puede ser responsable de un cuasidelito de homicidio o de lesiones, si es que estos resultados son la realización de un riesgo consecuencial pero inherente a la conducción de esa clase de vehículos, es decir, de un riesgo que estaba obligado a neutralizar. Lo que ocurre es que en muchas de estas hipótesis puede resultar particularmente difícil establecer qué riesgo se ha realizado o, peor aún, cuál de todos los riesgos observados en la especie constituye la explicación prevalente del resultado. A esta dificultad se añaden las consideraciones de imputación subjetiva y el problema de los daños que se producen, al menos en parte, como consecuencia de la acción u omisión de otras personas, incluida la propia víctima. Precisamente aquí es donde encuentra sentido una figura como la establecida en el artículo

evitables en forma autónoma”. Este punto de vista, sin embargo, pone excesivo énfasis en uno de los aspectos -la evitabilidad autónoma de las consecuencias ulteriores-, dejando de lado la competencia por el riesgo, que solo es resistente al efecto exonerador del riesgo permitido cuando se está ante un riesgo especial o, en el caso de las conductas justificadas, en los estrictos límites de la norma permisiva. Por la misma razón, tampoco parece de recibo la posibilidad de interpretar la conducta del omitente como "interrupción de un curso causal salvador" al cual el lesionado en el accidente tendría derecho, como ha sugerido para constelaciones análogas SiLVA SÁNCHEZ (2007) pp. 25 y ss. 
195 LT. Su función primaria consiste en evitar estos problemas de imputación en los casos de conducción dentro de los límites del riesgo permitido, permitiendo la atribución de un delito de peligro respecto de los mismos bienes jurídicos, sancionado además con una pena relevante.

Por lo tanto, el juego de los tres últimos incisos del artículo 195 LT da lugar a tres hipótesis diversas, cuya aplicación dependerá de si se configura un delito o cuasidelito de homicidio y del efecto que tenga en el caso concreto la prohibición de doble valoración: (i) si se configura un delito o cuasidelito de homicidio o de lesiones, y para la imputación de este y del delito de omisión de auxilio no es necesario desvalorar dos veces un mismo hecho o segmento del hecho, el conductor puede ser responsable de aquel delito o cuasidelito y, además, de la omisión de auxilio; (ii) si se configura un delito o cuasidelito de homicidio o de lesiones, y la imputación de la omisión de auxilio resulta redundante desde la perspectiva del non bis in idem, solo se aplicará el respectivo delito o cuasidelito; (iii) si la imputación del delito o cuasidelito no resulta posible debido a que no se puede atribuir al conductor todos los elementos fundantes de tal responsabilidad, solo se aplicará la figura de omisión de auxilio.

Por otra parte, como la figura protege la vigencia de la prohibición de matar o lesionar a otro y, por lo tanto, solo tiene aplicación si el comportamiento precedente del conductor permite interpretar la omisión como infracción a esa prohibición, cuando el lesionado fallece de inmediato y cualquier ayuda carece de toda eficacia, al menos respecto de la omisión de auxilio solo podría entrar en consideración un delito putativo.

\section{c) Riesgos no IMPUTABLES}

Sintetizando lo expuesto hasta ahora se puede afirmar que debe existir una relación entre la conducta previa del agente y los resultados lesivos cuya presencia desencadena el deber de auxilio penalmente garantizado. La relación mínima es una de imputación objetiva a la conducción del vehículo, aun cuando tal conducción se haya mantenido dentro de los límites del riesgo permitido. En los casos de creación de un riesgo especial, el agente conserva una competencia preferente por el suceso incluso cuando no transgrede el riesgo permitido, salvo que las lesiones sean atribuibles a riesgos no imputables objetivamente al conductor, o bien, distintos de los que genera la conducción de vehículos. La observancia del riesgo permitido, sin embargo, modula la posición de garante e impide atribuir responsabilidad por un eventual delito de resultado en razón de la realización de la conducta riesgosa permitida, aunque subsista el deber jurídico-penalmente relevante de neutralizar los efectos ulteriores evitables.

Demos ahora un paso más y ahondemos en qué se quiere decir cuando se afirma que la relación que debe existir entre la conducción de un vehículo que ha participado en un accidente de tránsito y los resultados típicamente relevantes que activan el deber de auxilio penalmente garantizado, es una relación de imputación objetiva. Pues, en primer lugar, la creación de un riesgo especial solo deja subsistente la injerencia respecto de los riesgos residuales o colaterales de ese mismo riesgo especial. Por eso, no quedan cubiertos los casos en que no se realiza un riesgo residual de la conducción, sino que el daño se debe, por ejemplo, a la caída de un objeto contundente sobre la pista de circulación. 
Por otra parte, el riesgo especial solo tiene incidencia en una de las instituciones dogmáticas de la imputación objetiva de conductas, el riesgo permitido. Por lo tanto, podría ocurrir que ni siquiera surja un deber del conductor de neutralizar consecuencias ulteriores si es que otros institutos de imputación de conductas - principio de confianza, actuación a riesgo propio, prohibición de regreso- o de resultados lo impide. El desarrollo de estos aspectos excedería el objeto acotado de esta contribución, pero puede ser ilustrativo referirse al menos a los dos casos más relevantes para la praxis: las hipótesis de actuación a riesgo propio, donde es la misma víctima -usualmente, el peatón-quien provoca el accidente, y los casos en que es otro conductor el que ha infringido gravemente sus deberes, lo que ha provocado el accidente.

Consideremos en primer término las hipótesis en que es otro conductor el que, como consecuencia de una vulneración grave de sus deberes como participante en el tráfico, produce el accidente. El principio de confianza es el principio jurídico según el cual, a pesar de la experiencia de que las personas cometen errores e incluso delitos, el sujeto no está obligado a incluir en su planificación errores o faltas graves de quienes interactúan con él $^{37}$. Este principio gobierna las relaciones de responsabilidad entre quienes son garantes, como es el caso de quienes participan en el tráfico motorizado. Si el accidente se produjo porque otro conductor hizo caso omiso de una luz roja, será este conductor quien quede vinculado por el deber de auxilio penalmente garantizado. Esta transgresión grave -el principio de confianza no opera respecto de transgresiones leves o cotidianas- desplaza la competencia de los demás conductores por el suceso. Esto no significa que los demás conductores queden jurídicamente eximidos de prestar auxilio; muy por el contrario, todos quedarán obligados en virtud del artículo 176 LT y podrían ser sancionados conforme al artículo 201 $\mathrm{N}^{\circ} 15$ LT.

En los accidentes que son provocados por la conducta abiertamente temeraria de la víctima se está, jurídicamente hablando, ante casos de autolesión. En esta segunda constelación, la autonomía de la víctima excluye la posibilidad de atribuir la lesión a un tercero, aunque la conducta de este forme parte de su explicación causal. Para que opere la actuación a riesgo propio es necesario que concurran ciertas condiciones, a saber y en síntesis, que el riesgo realizado sea el que ha asumido la víctima, que no exista instrumentalización u otra disminución relevante de su autonomía y que quien interactúa con ella no esté vinculado por un particular deber de protección, distinto del principio neminem laedere o en el ámbito de aplicación de un deber institucional. En la medida en que se verifiquen estas condiciones, sin embargo, desaparecerá el vínculo mínimo que ha de existir, según la posición aquí sostenida, entre el comportamiento del conductor y las lesiones que desencadenan el deber de auxilio garantizado penalmente en el artículo 195 LT.

La situación del peatón que se arroja sorpresivamente bajo las ruedas de un vehículo que circula reglamentariamente por la calle debe asimilarse, sin embargo, a la primera

37 Véase sobre el principio como delimitación negativa del deber de cuidado Maraver (2009) pp. 273 y ss.; véase también VAN WEEZEL (2006) pp. 219 y ss. El artículo 144 inciso $2^{\circ}$ LT, que exige conducir atento a las condiciones del tránsito, modula en este ámbito el alcance del principio de confianza, pero ciertamente no lo suprime: el tráfico vial es posible precisamente gracias la autorización para excluir de la planificación individual la comisión de delitos o graves faltas de los demás partícipes. 
constelación ${ }^{38}$, pues en el tráfico vial tanto los conductores como los peatones son garantes de que en sus interacciones no se produzcan resultados lesivos. Por eso, la delimitación de sus ámbitos de responsabilidad se realiza con arreglo a los criterios del principio de confianza, conforme al cual solo las infracciones menores de los demás participantes en el tráfico deben ser incorporadas en la planificación de cada actor. En esta hipótesis, pues, no se trata de que el peatón no haya adoptado las medidas que le incumbían para protegerse y que de este modo la creación del riesgo especial por parte del automovilista resulte compensada por la conducta de la víctima. La imputación resulta excluida por el principio de confianza.

Un análisis paralelo debe hacerse respecto de los criterios de imputación objetiva de resultados. Cuando el riesgo que se realizó no es reconocible como un riesgo del tráfico vial, ni siquiera uno residual, o cuando es completamente ajeno al accidente mismo, también debe descartarse la vinculación mínima que debe existir entre la conducción y los resultados lesivos típicamente relevantes. La determinación de la "tipicidad" del riesgo puede hacerse, entre otras fuentes, con ayuda de la experiencia cristalizada en jurisprudencia y en las coberturas consideradas por la industria de los seguros para vehículos y personas ${ }^{39}$.

Como salta a la vista, las discusiones de detalle en torno a la aplicación de estos institutos en el caso concreto pueden ser abundantes y complejas. Sin embargo, el criterio propuesto es claro: no hay un deber de auxilio penalmente garantizado sin que el conductor tenga, al menos, el deber de neutralizar daños consecuenciales de la conducta riesgosa pero permitida. Las diferencias que corresponda hacer entre quienes sean competentes por haber transgredido el riesgo permitido y quienes lo sean únicamente en virtud de la creación de un riesgo permitido especial, y que no se traduzcan en un concurso real con el delito o cuasidelito de homicidio o lesiones, encontrarán su lugar en el ámbito -muy restringido por la LEY N ${ }^{\circ} 20.770$ de 2014- de la determinación de la pena.

\section{EL ALCANCE DEL ARTíCULO 201 Nº 15 DE LA LEY DE TRÁNSITO}

La interpretación precedente determina a su vez el alcance del artículo $201 \mathrm{~N}^{\circ} 15 \mathrm{LT}$.

Este precepto enumera entre las infracciones o contravenciones menos graves la de no cumplir las obligaciones que impone el artículo 176, sin mayor especificación. Resulta entonces que en la misma LT se definen dos ilícitos formalmente idénticos en cuanto a la norma de conducta, pero mientras uno de ellos es considerado de índole penal y contempla sanciones privativas de libertad, el otro no pasa de constituir una contravención equivalente a estacionar en doble fila o no señalizar antes de virar y menos grave que vulnerar la restricción vehicular, cuyo conocimiento corresponde a la justicia de policía local. No existen antecedentes histórico-legislativos relevantes que permitan desentrañar el sentido de esta

\footnotetext{
38 Como en los hechos que subyacen a la sentencia de la Corte de Santiago en Contra D.A.C.S. (2015) y a la sentencia de la Corte Suprema en Contra MARCo ANTONio MARTÍNEZ CARCAMo (2017).

39 Un estudio bastante pormenorizado de los riesgos que pertenecen al tráfico vial, precisamente a la luz de los riesgos cubiertos en las pólizas de seguros, puede verse en Dopico (2002) pp. 273 y ss.
} 
duplicidad, salvo el hecho de que la contravención existía ya mucho antes de que se estableciera el delito de omisión de auxilio ${ }^{40}$.

La subsistencia de esta disposición echa por tierra, al menos desde el punto de vista sistemático, cualquier pretensión de fundar el delito del artículo 195 LT en consideraciones de solidaridad general. En efecto, la única explicación sistemáticamente viable para la coexistencia de los dos ilícitos es el fundamento de la obligación de detenerse y auxiliar, es decir, la especie del deber quebrantado. Como en ambos casos el sujeto activo del delito es solo el conductor, y no otra persona, la única diferencia posible tiene que decir relación con la conducción del vehículo, en la medida en que el despliegue de esta actividad afecta de algún modo la esfera de derechos de otras personas con las que el conductor no tiene vínculo alguno. Se trata, pues, de un deber fundado en la injerencia, y lo primero que hay dilucidar es si tal posición de garante se activa solo cuando se ha transgredido el riesgo permitido o si, en cambio, basta con la creación de un riesgo especial.

Ya se ha visto que la construcción legal de la figura sugiere que el deber de auxilio surge también a propósito de una conducción que no ha excedido el riesgo permitido. El riesgo especial así modulado reduce la contravención del artículo $201 \mathrm{~N}^{\circ} 15 \mathrm{LT}$ a los casos de lesiones no imputables a la conducción ni atribuibles siquiera a la realización del riesgo residual inherente a ella: el atropellado se arrojó sorpresivamente bajo las ruedas, un neumático lanzó despedido un objeto no visible para el conductor que impactó a un transeúnte, etc. En estos casos subsiste un deber puro de solidaridad, cuya infracción se encuentra sancionada por una regla de índole contravencional, lo que valorativamente armoniza con el $494 \mathrm{~N}^{\circ} 14 \mathrm{CP}$.

Así, el conductor "mal samaritano" quedará sujeto al régimen contravencional de la LT, mientras que los demás partícipes en el accidente quedarán sometidos, igual que los transeúntes, al régimen de las faltas del Código Penal y del Código Procesal Penal. Esta curiosa diferencia de tratamiento podría verse compensada, sin embargo, por el hecho de que los presupuestos de aplicación de la falta son más exigentes, pues se requiere que la víctima se encuentre en despoblado, lo que al menos supondrá que el conductor del vehículo se haya dado a la fuga o no esté en condiciones de prestar ayuda alguna.

\section{LA POSICIÓN DE LA JURISPRUDENCIA}

El nuevo delito de omisión de auxilio en caso de accidente solo cuenta tres años de vigencia, pero en este periodo de tiempo ya es posible observar una clara evolución jurisprudencial.

En diciembre de 2015 y a comienzos de 2016, las Cortes de Apelaciones de Santiago y de Concepción establecieron en sendos fallos de nulidad que la figura del artículo 195 LT únicamente puede tener aplicación si el conductor en cuestión se encontraba en estado de

40 En la versión original de la Ley de Tránsito (Ley N 18.290 de 1984), la contravención se encontraba en el artículo $199 \mathrm{~N}^{\circ} 16$, en relación con el artículo 183. 
ebriedad o bajo el efecto de sustancias prohibidas ${ }^{41}$. Es decir, la omisión de auxilio era una figura subordinada al delito de conducción en estado de ebriedad con resultado de lesiones graves o muerte.

Es interesante observar cómo la Corte de Santiago identifica acertadamente el problema: se trata de encontrar un "criterio exegético" capaz de dilucidar "[1] la existencia de preceptos que, en forma paralela, asignan distinta gravedad a idénticas conductas omisivas y [2] la razonabilidad y justificación de la gran entidad de la pena asignada al comportamiento" ${ }^{2}$. Los argumentos a favor y en contra del criterio escogido, la mayoría de los cuales gira en torno a la historia de la Ley $N^{\circ} 20.770$ de 2014, fueron reseñados precedentemente. Con independencia de su relativa plausibilidad, sin embargo, esta interpretación ha sido abandonada para dar paso a aquella que considera la omisión de auxilio como un delito "autónomo", tanto respecto de un eventual cuasidelito como en relación con el delito de conducción en estado de ebriedad o bajo la influencia de sustancias estupefacientes o psicotrópicas.

En este sentido han venido pronunciándose los tribunales de juicio oral en lo penal: el deber de auxilio concierne a "todo conductor que participe en los hechos, sin que se requiera (...) una participación directa en los mismos, mucho menos relativa a la responsabilidad penal que de ellos pudiere derivar" ${ }^{43}$. O bien: "Este ilícito no es accesorio como lo sostiene la defensa, por el contrario uno de los objetivos de la Ley $\mathrm{N}^{\circ} 20.770$ de 2014 (...) fue aumentar ciertas penas e incorporar nuevos delitos, entre ellos establecer un tipo penal especial e independiente destinado a sancionar a la persona que participa en un accidente automovilístico, no se detiene, no ayuda y no da cuenta del hecho a la autoridad"44.

Este mismo criterio es asumido por el Tribunal Constitucional al pronunciarse sobre requerimientos de inaplicabilidad por inconstitucionalidad que han incidido en diversos aspectos del artículo $195 \mathrm{LT}^{45}$.

Recientemente, la Sala Penal de la Corte Suprema tomó posición sobre las relaciones entre la responsabilidad por el accidente y el delito de omisión de auxilio, confirmando la tendencia descrita. La sentencia afirma la autonomía del delito de omisión de auxilio basándose en dos argumentos.

El primero se construye a partir de la regla concursal del inciso final del artículo 195 LT, que expresamente prevé la posibilidad de imponer dos sanciones, una por la omisión de auxilio y otra por el respectivo delito o cuasidelito: "La ley no sanciona en estas normas el hecho causante de las lesiones o la muerte ni la conducción en estado de ebriedad, bajo los

41 CONTRA D.A.C.S. (2015); CONTRA F.A.J.O.R. Y OTROS (2016); en este último caso, el acusado había sido absuelto de los respectivos cuasidelitos de homicidio y lesiones graves y, en la misma sentencia, condenado por el delito de omisión de auxilio.

42 CONTRA D.A.C.S. (2015) considerando $5^{\circ}$.

43 Contra Conzalo CRISTí́n Rojas TorRes y OtRa (2015) considerando $19^{\circ}$.

44 Contra Juan Carlos Ávila Moreno (2016) considerando $13^{\circ}$.

45 Véase especialmente el análisis de la historia de la disposición contenido en la sentencia del Tribunal Constitucional recaída en el Rol No 2897, Requerimiento de inaplicabilidad por inconstitucionalidad respecto de los artículos 195, 196 bis y 196 ter de la Ley $N^{o} 18.290$, modificada por la Ley $N^{\circ} 20.770$, considerandos $2^{\circ}$ a $13^{\circ}$. 
efectos del alcohol o de sustancias psicotrópicas o estupefacientes, pues se trata de un tipo penal autónomo, inteligencia que surge del tenor literal del inciso final del artículo 195, que regula aquellos casos en que se produzca un concurso de delitos, en que un mismo sujeto sea responsable de la muerte, lesiones y/o manejo en estado de ebriedad y, además, por el hecho típico independiente, como en este caso, consistente solo en el incumplimiento de la obligación de detener la marcha, prestar la ayuda posible y dar cuenta a la autoridad" 46 .

El segundo argumento utiliza el sentido que la expresión "partícipe" o "participar" tiene en la LT, donde carece de la connotación de "participación culpable" que es usual en los textos legislativos penales: "La expresión 'participe' que utiliza la norma del artículo 176 no atiende a esa condición [la de responsable del accidente]. La misma nomenclatura se contiene en el artículo 168 de la indicada normativa, al referirse a 'participantes' de un accidente de tránsito, concepto que difiere de 'responsables' del mismo. Así, la comprensión adecuada ciertamente lleva a sostener que las obligaciones que impone el artículo 176 tienen como destinatarios todos quienes formen parte de un accidente como conductores, independiente de sus posteriores y eventuales responsabilidades" ${ }^{37}$.

Sin embargo, el verdadero significado del fallo para la discusión que es objeto de estas reflexiones no se desvela hasta que se conocen los detalles de hecho del caso. En efecto, y según se relata en el considerando $7^{\circ}$, el acusado "conducía el día y a la hora del accidente, (...) vio a una persona que se lanzó al vehículo por el lado del acompañante a la que golpeó con el espejo. Miró por el retrovisor, lo vio de pie y siguió su marcha hacia su casa” ${ }^{\prime 8}$. Es decir, todo indica que se trata de un caso en que el accidente es objetivamente imputable a la actuación del peatón, que se arroja sorpresivamente sobre el auto que va pasando. Si esto es efectivo, entonces la sentencia de la Corte Suprema contiene una toma de posición a favor de la tesis que desvincula por completo la omisión de auxilio de la conducta precedente del conductor o, con otras palabras, que funda el deber de auxilio penalmente garantizado en un deber puro de solidaridad que se activa causalmente, incluso cuando el accidente y sus resultados no son siquiera objetivamente imputables al conductor.

Las razones por las cuales esta interpretación resulta incompatible con la configuración legal del delito ya han sido esbozadas.

\section{SÍNTESIS Y CONCLUSIONES}

En síntesis, todo conductor que se ha visto involucrado en un accidente de tránsito debe acudir en auxilio de quienes han sufrido lesiones. Sin embargo, el delito previsto en el artículo 195 LT exige que exista una cierta relación entre la conducción -el accidente previo- y los resultados de muerte o lesiones que hacen surgir el deber penal de auxilio.

Esta relación es una de imputación objetiva, por lo que es preciso convocar la teoría de las posiciones de garante y las instituciones dogmáticas de la imputación objetiva de conductas y de resultados. La relación de imputación objetiva existe también cuando

\footnotetext{
46 Contra MARCo ANTONio MARTÍNEZ CARCAMo (2017) considerando $5^{\circ}$.

47 Contra Marco ANTONio MARTÍNEZ CARCAMo (2017) considerando $6^{\circ}$.

48 Contra Marco ANTONio MARTÍNEZ CARCAMo (2017) considerando $7^{\circ}$.
} 
el conductor se mantiene dentro del riesgo permitido, pues la conducción de vehículos motorizados constituye un riesgo especial. La injerencia basada en la creación de un riesgo especial permitido no genera responsabilidad por las lesiones o la muerte que resulten inmediatamente de la conducción conforme a derecho, pero determina una competencia preferente del conductor por la neutralización de las consecuencias ulteriores y autónomamente evitables de la conducta permitida. La responsabilidad que surge de la infracción de este deber de neutralización adquiere la forma, en el artículo 195 LT, de un deber de auxiliar a quienes resulten lesionados, cuya infracción dolosa anticipa la punibilidad -al modo de una figura de peligro- en relación con la efectiva concreción de un riesgo consecuencial de la conducción.

El juego de los tres últimos incisos del artículo 195 LT da lugar entonces a diversas hipótesis, cuya aplicación depende de si se configura un delito o cuasidelito de homicidio y del efecto que tenga en el caso concreto la prohibición de doble valoración. Cuando se configura un delito o cuasidelito de homicidio o de lesiones, y para la imputación de este y del delito de omisión de auxilio no es necesario desvalorar dos veces un mismo hecho o segmento del hecho, el conductor puede ser responsable de ambos delitos. En cambio, si la imputación del delito o cuasidelito no resulta posible debido o la imputación de la omisión de auxilio resultaría redundante desde la perspectiva del non bis in idem, solo se aplicará, en su caso, la figura de omisión de auxilio o el delito o cuasidelito de homicidio o de lesiones.

\section{BIBLIOGRAFÍA CITADA}

Baldó Lavilla, Francesc (1994): Estado de necesidad y legitima defensa. Un estudio sobre las "situaciones de necesidad" de las que derivan facultades y deberes de salvaguarda (Barcelona, J.M. Bosch).

Biblioteca del Congreso Nacional: Historia de la Ley $\mathrm{N}^{\circ}$ 20.770. Disponible en: http:// www.bcn.cl/ historiadelaley/nc/historia-de-la-ley/4318/ (consultada el 7 de diciembre de 2017).

Coca Vila, Ivó (2016): La colisión de deberes en Derecho penal. Concepto y fundamentos de solución (Barcelona, Atelier).

Contreras, Lautaro (2017): "La posición de garante del fabricante en el Derecho penal alemán”. Política criminal, Vol. 12, No 23: pp. 1-55.

Cury, Enrique (2005): Derecho Penal. Parte General (Santiago, Ediciones Universidad Católica de Chile, $8^{\mathrm{a}}$ ed.).

Dopico, Jacobo (2002): "Omisión de socorro tras accidente fortuito. La imputación de sucesos lesivos a conductas lícitas”, Anuario de Derecho Penal y Ciencias Penales, Vol LV: pp. 235-284.

Escobar, Javier (2017): "Sobre el sujeto activo del 'delito de fuga' prescrito y sancionado en el artículo 195 de la ley No 18.290" (artículo citado pro manuscripto).

Freund, Georg (2009): Strafrecht Allgemeiner Teil (Berlin, Springer, 2a ed.).

Hernández, Héctor (2006): "El problema de la 'causalidad general' en el derecho penal chileno (con ocasión del art. 232 del Anteproyecto de Nuevo Código Penal)”. Política crimiminal $\mathrm{n}^{\circ} 1$ : pp. 1-33. 
Hernández, Héctor (2011): “Art. 1 ${ }^{\circ}$ ”, en Couso, Jaime y Hernández, Héctor (dirs.), Código Penal Comentado. Parte General (Santiago, Thomson Reuters).

Herzberg, Rolf (1986): “Zur Garantenstellung aus vorangegangenem Tun”, Juristenzeitung 1986, pp. 986-992.

JAKOBS, Günther (2012): System der strafrechtlichen Zurechnung (Frankfut a.M., Vittorio Klostermann).

JAKOBS, Günther (2013): "Recht und Gut - Versuch einer strafrechtlichen Begriffsbildung", en Freund, Georg et al. (eds.), Grundlagen und Dogmatik des gesamten Strafrechtssystems. Festschrift für Wolfgang Frisch zum 70. Geburtstag (Berlin, Duncker \& Humblot), pp. 81-94.

JAKOBS, Günther (2017a): "Strafrechtliche Zurechnung und die Bedingungen der Normgeltung”, en ÉL MISMO, Strafrechtswissenschaftliche Beiträge - edición al cuidado de Michael Pawlik (Tübingen, Mohr Siebeck), pp. 163-179.

Kindhäuser, Urs (2015): Strafrecht. Allgemeiner Teil (Baden-Baden, Nomos, $7^{\text {a }}$ ed.).

KöHLER, Michael (1997): Strafrecht Allgemeiner Teil (Berlin, Springer).

Kubiciel, Michael (2013): Die Wissenschaft vom besonderen Teil des Strafrechts (Frankfurt a.M., Vittorio Klostermann).

Kudlich, Hans (2012): "Kommentierung zum \ 13 StGB”, en Satzger, Helmut, SchluckeBIER, Wilhelm y Widmaier, Gunter (2012): Strafgesetzbuch (Köln, Carl Heymanns, 2a ed.).

Mañalich, Juan Pablo (2015): "La imprudencia como estructura de imputación", Revista de Ciencias Penales, Vol. XLII, No 3, pp. 13-36.

MaraVER, Mario (2009): El principio de confianza en Derecho penal. Un estudio sobre la aplicación del principio de autorresponsabilidad en la teoría de la imputación objetiva (Madrid, Civitas).

Matus, Jean Pierre (2014): "Ley Emilia", Revista Doctrina y Jurisprudencia Penal, Relevancia Jurídica del Tráfico Vial (Edición Especial): pp. 101-113.

Merkel, Adolf (1899): Gesammelte Abhandlungen aus dem Gebiet der allgemeinen Rechtslehre und des Strafrechts, 2. Teil (Strassburg, K. J. Trübner).

PaWlik, Michael (2012): Das Unrecht des Bürgers (Tübingen, Mohr Siebeck).

RenZIKOwski, Joachim (2013): "Solidarität in Notsituationen. Ein historischer Überblick von Thomas v. Aquin bis Hegel“, en A. von Hirsch; U. Neumann; K. Seelmann (edit.), Solidarität im Strafrecht. Zur Funktion und Legitimation strafrechtlicher Solidaritätspflichten (Baden-Baden, Nomos), pp. 13 y ss.

ReYes, Italo (2015): "Sobre la construcción de la exigencia de cuidado”. Política criminal, Vol. 10, No 19: pp. 56-91.

Robles Planas, Ricardo (2010): "En los límites de la justificación. La colisión de intereses vitales en el ejemplo del derribo de aviones y otros casos trágicos”, en D. Luzón (dir.), Derecho penal del estado social y democrático de derecho. Libro homenaje a Santiago Mir Puig (Madrid, La Ley), pp. 445-473.

Roxin, Claus (1970): Offene Tatbestände und Rechtspflichtmerkmale (Berlin, De Gruyter, 2a ed.). 
SÁnchez-Vera, Javier (1999): Pflichtdelikt und Beteiligung (Berlin, Duncker \& Humblot, 1999).

Silva Sánchez, Jesús María (2007): "Derechos de necesidad agresiva y deberes de tolerancia”, Revista Discusiones, N 7: pp. 25-56.

Stratenwerth, Günter y Kuhlen, Lothar (2011): Strafrecht Allgemeiner Teil (Vahlen, München, $6^{\mathrm{a}}$ ed.).

Stree, Walter y Bosch, Nikolaus (2014): “Comentario al $\$ 13$ ”, en Schönke/Schröder, Strafgesetzbuch (München, C. H. Beck, 29a ed.).

VAn WeEzel, Alex (2006): Beteiligung bei Fahrlässigkeit. Ein Beitrag zur Verhaltenszurechnung bei gemeinsamem Handeln (Berlin, Duncker \& Humblot).

VAN WeEZel, Alex (2007): "Autoría y responsabilidad por el producto: ¿Participación en decisiones de órganos colegiados de la empresa como intervención delictiva?", en E. Montealegre (coord.), Derecho penal y sociedad, Tomo II, (Bogotá, Ediciones Universidad Externado de Colombia): pp. 51-72.

Van Weezel, Alex (2008): Error y mero desconocimiento en derecho penal (Santiago, Abeledo Perrot).

Van Weezel, Alex (2013): "Actuar en lugar de otro", en Mañalich, J. P. (coord.), La ciencia penal en la Universidad de Chile. Libro Homenaje a los Profesores del Departamento de Ciencias Penales de la Facultad de Derecho de la Universidad de Chile (Santiago, 2013).

VAn WeEzel, Alex (2014): "Solidaridad en el tráfico motorizado. El delito de omisión de auxilio en caso de accidente", Doctrina y Jurisprudencia Penal, Edición Especial: pp. 191-204.

VArgas, Tatiana (2015): “Caso Chépica. SCS, 4/08/1998, Rol 1338-1998”, en ELLA Misma, Casos destacados de derecho penal. Parte general (Santiago, Thomson Reuters).

Welp, Jürgen (1971): "Anmerkung zu BGH, Urteil v. 29.7.1970 - 2 StR 221/70 (LG Trier)", Juristenzeitung 1971: pp. 432-434.

Wessels, Johannes; BeulKe, Werner; Satzger, Helmut (2015): Strafrecht Allgemeiner Teil (München, C. F. Müller, $45^{\circ}$ ed.).

Wilenmann, Javier (2014): Freiheitsdistribution und Verantwortungsbegriff (Tübingen, Mohr Siebeck).

Wilenmann, Javier (2017): La justificación de un delito en situaciones de necesidad (Madrid / Barcelona / Buenos Aires / Sao Paulo, Marcial Pons).

\section{NORMAS CITADAS}

LEY N 20.770 (16/09/2014), Modifica la ley del tránsito, en lo que se refiere al delito de manejo en estado de ebriedad, causando lesiones graves, gravísimas o, con resultado de muerte.

LEY N 18.290 (07/01/1984), Ley de Tránsito, actualmente contenida en el Decreto con Fuerza de Ley $\mathrm{N}^{\circ} 1(27 / 12 / 2007)$.

LEY $N^{\circ} 20.068(10 / 12 / 2005)$, Introduce diversas modificaciones a la Ley No 18.290, en materia de tránsito terrestre. 


\section{JURISPRUDENCIA CITADA}

REQUERIMIENTO DE INAPLICABILIDAD POR INCONSTITUCIONALIDAD RESPECTO DE LOS ARTÍCULOS 195, 196 BIS Y 196 TER DE LA LEY No 18.290, MODIFICADA POR LA LEY No 20.770, EN EL MARCO DE LOS AUTOS PENALES RIT 1479-2015, RUC 1500116832-8 DEL $9^{\circ}$ JUZGADO DE GARANTÍA DE SANTIAGO: Tribunal Constitucional chileno, Rol No 2897, 4 de julio de 2017.

Contra Pablo Ignacio Arrocet Solís (2015): Tribunal de Juicio Oral en lo Penal de La Serena, 8 de septiembre de 2015 (sentencia definitiva en juicio oral).

Contra N.A.G.O. (2016): Corte de Apelaciones de Punta Arenas, 30 de mayo de 2016 (recurso de nulidad), en VLEX, Identificador 641191153, fecha de consulta 22 de junio de 2016.

Contra D.A.C.S. (2015): Corte de Apelaciones de Santiago, 31 de diciembre de 2015 (recurso de nulidad), en VLEX, Identificador 590891274, fecha de consulta 19 de junio de 2016.

Contra Mauricio Orlando Ortega Ruiz (2017): Corte Suprema, 11 de julio de 2017, Rol 19.008-17 (recurso de nulidad).

Contra Marco Antonio Martínez CÁRcamo (2017): Corte Suprema, 20 de septiembre de 2017, $\mathrm{N}^{\circ} 35.715-17$ (recurso de nulidad).

Contra Carlos Humberto Castro Muñoz (1998): Corte Suprema, 4 de agosto de 1998, Rol N ${ }^{\circ}$ 1338-1998 (recursos de casación en la forma y en el fondo).

Contra Gonzalo Cristián Rojas Torres y otra (2015): Tribunal de Juicio Oral en lo Penal de Viña del Mar, 3 de junio de 2015, RUC 1400905152-0, RIT 89-2015 (sentencia definitiva en juicio oral).

Contra Juan Carlos Ávila Moreno (2016): Tribunal de Juicio Oral en lo Penal de Melipilla, 12 de marzo de 2016, RUC 1500105538-8, RIT 2-2016 (sentencia definitiva en juicio oral).

Contra F.A.J.O.R. Y OtRos (2016): Corte de Apelaciones de Concepción, 11 de marzo de 2016, en VLEX, Identificador 628407782, fecha de consulta 15 de junio de 2016 (recurso de nulidad). 